\title{
Inheritance and molecular mapping of a gibberellin-insensitive dwarf mutant in groundnut (Arachis hypogaea L.)
}

\author{
Suvendu Mondal • Anand M. Badigannavar • \\ S. F. D'Souza
}

Received: 3 August 2010/Revised: 30 September 2010 /Accepted: 6 October 2010 / Published online: 3 November 2010

(C) Institute of Plant Genetics, Polish Academy of Sciences, Poznan 2010

\begin{abstract}
A dark green dwarf mutant, TGM 167, was isolated from a gamma ray + sodium azide mutagenised population of cultivated groundnut breeding line, TFDRG 5. The mutant had a $45.8 \%$ reduction in height due to its shorter internodal length. Further, it was found to be insensitive towards exogenous $\mathrm{GA}_{3}$ application, although it had nearly the same level of endogenous $\mathrm{GA}_{3}$ as the parent. Genetic analysis revealed that the dwarfism is under the control of a single dominant gene. This dominant dwarfing gene was mapped with an SSR marker TC3H02 at a distance of $9.7 \mathrm{cM}$.
\end{abstract}

Keywords Arachis hypogaea . Dwarf mutant - Gamma rays $\cdot$ Gibberellin $\cdot$ Sodium azide $\cdot$ SSR markers

Reduced plant height is an important agronomic trait associated with yielding capacity and lodging resistance in crop plants. A large number of dwarf mutants were isolated in different crop species and several of them have been characterised as gibberellic acid (GA) deficient or insensitive mutants. Either the disruption or abnormal synthesis of GA or the disruption of GA signal transduction can lead to dwarfism (Ueguchi-Tanaka et al. 2000). A common feature of GA-sensitive mutants is that they are recessive and deficient for GA because of a block in their biosynthetic pathway (Phinney 1984). Groundnut (Arachis hypogaea L.) is an important oilseed crop grown extensively in subtropical regions. Groundnut dwarf mutants were induced using X-rays (Patil 1966), gamma rays (Patil and Mouli 1978; Badigannavar and Mondal 2010), laser (Bozhan et al.

S. Mondal $(\bowtie) \cdot$ A. M. Badigannavar · S. F. D’Souza

Nuclear Agriculture and Biotechnology Division,

Bhabha Atomic Research Centre (BARC),

Mumbai 400085, India

e-mail: suvenduhere@yahoo.co.in
1997), diethyl sulfate (Ashri 1970), ethyl methane sulfonate (Gowda et al. 1996), ethidium bromide (Levy and Ashri 1975) and colchicine (Tiwari and Khanorkar 1984). Although enough information is available for the isolation of induced mutants in groundnut, their characterisation at biochemical and molecular levels is lacking. The present study reports on the isolation of a dominant dwarf mutant in groundnut and its preliminary biochemical and molecular characterisation.

Dry seeds (8-10\% moisture) of TFDRG 5 (A. hypogaea ssp. fastigiata var. vulgaris) were treated with gamma rays (200 and $300 \mathrm{Gy)}$ and/or sodium azide $\left(\mathrm{NaN}_{3} 1,2\right.$ and $3 \mathrm{mM}$ ) singly or as a combination of both (Badigannavar et al. 2005; Mondal et al. 2007). The $\mathrm{M}_{2}$ population having 20,619 plants was grown in the field during the rainy season (June to September) of 2004 and the dwarf mutant, TGM 167, was isolated along with other morphological and yield-related mutants and tested for their true breeding behaviour in the $\mathrm{M}_{3}$ and subsequent generations. TGM 167 belongs to botanical type A. hypogaea ssp. fastigiata var. vulgaris, like its parent. Further, all of the true breeding mutants, including TGM 167, were evaluated for their agronomic performances in the $\mathrm{M}_{8}$ (rainy season 2007) and $\mathrm{M}_{9}$ (summer 2008) generations and the agronomic data were analysed using IRRISTAT 2.0 software (International Rice Research Institute [IRRI] 2003).

The dwarf mutant TGM 167 was crossed with TFDRG 5. Segregation data for plant height in the $F_{2}$ and $F_{3}$ plants were subjected to the $\chi^{2}$ test for goodness of fit. A total of 1,114 published SSR primer pairs were screened between the parent and dwarf mutant. The SSR amplification, detection and data scoring were as described by Mondal and Badigannavar (2010). The polymorphic primer pairs were used for the genotyping of $73 \mathrm{~F}_{2}$ plants derived from TFDRG $5 \times$ TGM 167 and TGM $167 \times$ TFDRG 5 crosses. 
Kosambi map distances (Kosambi 1944) were estimated through linkage analysis between plant height segregation in the $\mathrm{F}_{2}$ population and SSR marker genotyping data using MAPMAKER version 3.0b (Lincoln et al. 1993) with a minimum LOD of 3.0.

Bioactive $\mathrm{GA}_{3}$ (Sigma, St. Louis, MO, USA) was dissolved in a small amount of absolute ethanol and diluted with distilled water. A field experiment was carried out by spraying $0,10,20,40,60,80$ and 100 ppm $\mathrm{GA}_{3}$ over the mutant in order to detect GA responsiveness. After 10 days of planting, the mutant and parent were sprayed daily until they were moist for a week in three replications, each consisting of ten plants. The height was measured from 40-day-old plants and compared with the untreated parent and mutant. In in vitro studies, surfacesterilised seeds $\left(0.1 \% \mathrm{HgCl}_{2}\right)$ of the mutant and parent were placed in conical flasks having Murashige and Skoog media $+1 \%$ agar-agar (Murashige and Skoog 1962) with and without $\mathrm{GA}_{3}$ at $10^{-8}, 10^{-7}, 10^{-6}, 10^{-5}, 10^{-4}$ and $10^{-3} \mathrm{M}$ in three replications. Each replication consisted of five flasks having four plants. The plants were grown at a 12/12-hday/night cycle and an average temperature of $28^{\circ} \mathrm{C}$. The plant height was measured after 30 days. $\mathrm{GA}_{3}$ responsiveness for lipase production was studied in groundnut by mimicking the studies of $\alpha$ amylase activity in embryo-less seed cotyledons in cereals. Hence, the lipase activity was chosen over $\alpha$ amylase as the groundnut is an oilseed crop and the main storage products are triglycerides (oils) rather than starch. Four to five embryo-less quarter cotyledons per plate were surfacesterilised, washed and positioned perpendicularly on a tributyrin agar plate $(5 \%$ tributyrin and $1.5 \%$ agar at $\mathrm{pH}$ 7.0) with or without $\mathrm{GA}_{3}\left(10^{-3}\right.$ to $\left.10^{-5} \mathrm{M}\right)$. The GA plates were prepared by adding filter-sterilised $\mathrm{GA}_{3}$ solution to cold medium. The plates were checked for the clear zone of lipid hydrolysis after seven days of incubation at $28 \pm$ $2^{\circ} \mathrm{C}$ in the dark. The quantification of endogenous $\mathrm{GA}_{3}$ was performed by gas chromatography fitted with a flame ionisation detector (GC 2014, Shimadzu, Kyoto, Japan). The apical meristem portion with two pairs of leaves was taken from 60-day-old plants of parent and mutant for $\mathrm{GA}_{3}$ extraction. The apical portion of the stem was ground to a fine powder in a mortar and pestle with liquid $\mathrm{N}_{2}$ and $\mathrm{GA}_{3}$ was extracted as per the method described by Reddy et al. (1989) for groundnut. Later, the extracts were esterified by the saponification-transesterification method using $0.5 \mathrm{~N} \mathrm{NaOH}$ in methanol and $10 \% \mathrm{BF}_{3}$ in methanol and were injected into gas chromatography apparatus. The gas chromatography chamber is equipped with an automated sampler, injector and a BP $1(25-\mathrm{m})$ capillary column (SGE Analytical Science Pvt. Ltd., Victoria, Australia) coated internally with a thin film $(0.25 \mu \mathrm{m}$ diameter $)$ of $100 \%$ dimethyl polysiloxane. The initial column temperature was $100^{\circ} \mathrm{C}$ and was held for $1 \mathrm{~min}$, followed by an increase to $265^{\circ} \mathrm{C}$ at the rate of $25^{\circ} \mathrm{C} / \mathrm{min}$. The injector and detector temperature were set to 320 and $300^{\circ} \mathrm{C}$, respectively. Gas flow rates of 3.5 (column flow), 30 and $300 \mathrm{ml} / \mathrm{min}$ for $\mathrm{N}_{2}$, $\mathrm{H}_{2}$ and air, respectively, were maintained. The $\mathrm{GA}_{3}$ content in the mutant and parent was identified and quantified by comparing the retention time of standard $\mathrm{GA}_{3}$ (Sigma, St. Louis, MO, USA) under the same temperature conditions and gas flow rates.

In the present study, a dwarf mutant TGM 167 was isolated from the treatment of 200 Gy gamma rays $+1 \mathrm{mM}$ $\mathrm{NaN}_{3}$ with a mutation frequency of $4.85 \times 10^{-5}$. In the $\mathrm{M}_{3}$ generation, dwarf plant bred true with a significant reduction in height as compared to the parent. The dwarf phenotype was maintained in TGM 167 from seed emergence until maturity. The plant height in TGM 167 was reduced by $45.8 \%$ as compared to TFDRG 5 (Table 1). Although there was no reduction in the number of internodes on the main axis in the mutant and parent, the internodal length was considerably shortened in the mutant (Table 1). Similar pod yield and shelling percentage with slightly reduced seed size was observed in TGM 167 as compared to TFDRG 5. All of the $F_{1}$ plants from both direct and reciprocal crosses between the parent and mutant were dwarf, indicating the absence of involvement of cytoplasmic factors. The $F_{2}$ plants were segregated as 3 dwarf: 1 normal height. The segregation in the $F_{3}$ plants was 1 (all dwarf): 2 segregating ( 3 dwarf: 1 normal height): 1 (all normal height) (Table 2). Both phenotypic and genotypic segregation revealed that dwarf trait in the mutant was conditioned by a single dominant gene. Most of the earlier studies reported that genes for dwarf mutants in groundnut were recessive (Ashri 1968; Patil and Mouli 1975; Bhuiyan 1984), dominant with recessive lethal effect (Ashri 1970) and incomplete dominant (Branch and Hammons 1983;

Table 1 Agronomic performances of the dwarf mutant TGM 167 in $\mathrm{M}_{8}$ and $\mathrm{M}_{9}$ generations as compared with TFDRG 5

\begin{tabular}{llllll}
\hline Traits & \multicolumn{2}{c}{ (Parent) } & & (Mutant) \\
\cline { 2 - 3 } \cline { 5 - 6 } \cline { 5 - 6 } & 2007 & 2008 & & $2007\left(\mathrm{M}_{8}\right)$ & $2008\left(\mathrm{M}_{9}\right)$ \\
\hline Plant height (cm) & 46.1 & 39.3 & & $25.7^{*}$ & $20.6^{*}$ \\
Number of internodes & 21.3 & 19.0 & & 20.8 & 17.8 \\
Internodal length (cm) & 2.16 & 2.07 & & $1.23^{*}$ & $1.15^{*}$ \\
Number of branches & 8.4 & 7.9 & & 10.2 & $10.2^{*}$ \\
Pod weight/plant (g) & 20.8 & 21.3 & & 23.5 & 21.2 \\
Seed weight/plant (g) & 15.2 & 15.4 & & 16.8 & 15.1 \\
Shelling outturn (\%) & 73.5 & 72.3 & & 71.4 & 71.1 \\
100 kernel weight (g) & 48.7 & 50.3 & & $40.3^{*}$ & $45.4^{*}$ \\
\hline
\end{tabular}

*Significantly different from the parent at $p=0.05$ 
Table 2 Inheritance of dwarfness in $F_{2}$ and $F_{3}$ plants of reciprocal crosses between the dwarf mutant TGM 167 and the parent TFDRG 5

\begin{tabular}{|c|c|c|c|c|c|}
\hline Generation & $\begin{array}{l}\text { Number of } \\
\text { progenies }\end{array}$ & $\begin{array}{l}\text { Number of } \\
\text { dwarf } \\
\text { plants }\end{array}$ & $\begin{array}{l}\text { Number of } \\
\text { normal } \\
\text { plants }\end{array}$ & $\chi^{2}(\mathrm{df})$ & $\begin{array}{l}p \text { - } \\
\text { value }\end{array}$ \\
\hline
\end{tabular}

\begin{tabular}{|c|c|c|c|c|c|}
\hline \multicolumn{6}{|c|}{ TFDRG $5 \times$ TGM 167} \\
\hline $\mathrm{F}_{1}$ & - & 2 & - & \multirow{3}{*}{$0.04(1)$} & \multirow{3}{*}{0.84} \\
\hline $\mathrm{F}_{2}$ & 2 & 26 & 8 & & \\
\hline \multirow[t]{4}{*}{$\mathrm{F}_{3}$} & 10 & 194 & 0 & & \\
\hline & 16 & 345 & 115 & $0.00(1)$ & 1.00 \\
\hline & 8 & 0 & 262 & & \\
\hline & \multicolumn{3}{|c|}{ Genotypic segregation $(1: 2: 1)$} & $0.35(2)$ & 0.84 \\
\hline \multicolumn{6}{|c|}{ TGM $167 \times$ TFDRG 5} \\
\hline $\mathrm{F}_{1}$ & - & 2 & - & \multirow{3}{*}{$0.42(1)$} & \multirow{3}{*}{0.52} \\
\hline $\mathrm{F}_{2}$ & 2 & 31 & 8 & & \\
\hline \multirow[t]{4}{*}{$\mathrm{F}_{3}$} & 12 & 297 & 0 & & \\
\hline & 19 & 329 & 112 & \multirow[t]{2}{*}{$0.04(1)$} & \multirow[t]{2}{*}{0.84} \\
\hline & 8 & 0 & 275 & & \\
\hline & \multicolumn{3}{|c|}{ Genotypic segregation $(1: 2: 1)$} & $0.85(2)$ & 0.65 \\
\hline Pooled $\mathrm{F}_{2}$ & 4 & 57 & 16 & $0.37(1)$ & 0.54 \\
\hline \multicolumn{4}{|c|}{ Homogeneity } & $0.09(1)$ & 0.76 \\
\hline
\end{tabular}

Badigannavar and Mondal 2010). This is the first known report of a dominant dwarf mutant in groundnut.

The molecular mapping of agronomically important traits in groundnut is very limited. Lower molecular polymorphism is a common feature in cultivated groundnut due to a recent event of monophyletic origin followed by genome duplication (Moretzsohn et al. 2005). In our study, the screening of 1,114 published SSR markers between the parent and mutant revealed that only seven $(0.63 \%)$ (TC3H02, TC3E02, TC11H06, IPAHM 659, IPAHM 468, EM 31 and pPGPseq 2H08) were polymorphic. The very low SSR polymorphism $(0.63 \%)$ between the parent and mutant was expected, as induced mutants have nearly identical genetic architecture to the parents. The genotyping of $F_{2}$ plants with all of these polymorphic SSR primers detected an expected 1:2:1 segregation for two markers (TC3H02 and IPAHM659) and the others had distorted ratios. Linkage analysis mapped $\mathrm{TC} 3 \mathrm{H} 02$ at $9.7 \mathrm{cM}$ from the dwarf locus in the mutant. The marker TC3H02 had also been mapped earlier to group I of the AA genome map (Moretzsohn et al. 2005) and linkage group Lg 5 in the SSR-based tetraploid linkage map (Hong et al. 2010) of groundnut.

Most of the plant species have the bioactive gibberellins in the form of $\mathrm{GA}_{3}$ and $\mathrm{GA}_{4}$. Previous reports in groundnut explained that $10 \mathrm{ppm} \mathrm{GA}_{3}$ was sufficient to induce height increment in a dwarf mutant with variable penetrance and expressivity (Ashri 1970). The spraying of $\mathrm{GA}_{3}(10,20,40$, 60,80 and $100 \mathrm{ppm}$ ) on the apical meristem of seedlings of
TGM $167(5.0-5.2 \mathrm{~cm})$ showed no response in plant height increment as compared to untreated mutant $(5.0 \mathrm{~cm})$ and treated or untreated parent $(12.5 \mathrm{~cm} ; \mathrm{LSD}=0.32$ at $p=0.05)$. Moreover, the mutant plants did not respond to the medium containing $\mathrm{GA}_{3}$ at different concentrations $\left(10^{-8}, 10^{-7}\right.$, $10^{-6}, 10^{-5}, 10^{-4}$ and $10^{-3} \mathrm{M}$ ) under in vitro study. Further, there was no differential response even at $10^{-3} \mathrm{M}$ (346 ppm) $\mathrm{GA}_{3}$ on lipase production in both the parent and mutant compared to the plate without $\mathrm{GA}_{3}$. Of the multiple peaks obtained using standard $\mathrm{GA}_{3}$ in gas chromatography, the major peak was observed at $9.5 \mathrm{~min}$. The quantitative analysis revealed that the $\mathrm{GA}_{3}$ content in the mutant $(132 \pm 7 \mathrm{ng} / \mathrm{g})$ was on a par with its parent $(130 \pm$ $11 \mathrm{ng} / \mathrm{g}$ of fresh weight). A similar phenomenon of accumulation of the same amount of native gibberellins in both the parent and mutant (D8) in maize explained a mutation in GA receptor that controls a product downstream from the binding of the bioactive GA to a receptor (Fujioka et al. 1988). Several such dominant dwarf mutants were reported in wheat and maize wherein mutation was detected in the orthologue of the Arabidopsis gibberellic acid-insensitive $(G A I)$ gene.

Acknowledgement Our special thanks go to Shri R. K. Sachan for the help in the field experiments.

\section{References}

Ashri A (1968) Morphology and inheritance of sterile brachytic dwarfs in peanuts, Arachis hypogaea. Crop Sci 8:413-415

Ashri A (1970) A dominant mutation with variable penetrance and expressivity induced by diethyl sulfate in peanuts, Arachis hypogaea L. Mutation Res 9:473-480

Badigannavar AM, Mondal S (2010) Induction of mutations for plant height and inheritance of dwarf mutant in groundnut (Arachis hypogaea L.) through gamma ray irradiation. Electronic J Plant Breed 1:156-161

Badigannavar AM, Kale DM, Mondal S, Murty GSS (2005) Trombay groundnut recombinants resistant to foliar diseases. Mutation Breeding Newslett Rev 1:11-12

Bhuiyan SA (1984) Inheritance of plant type in groundnut. Indian J Genet Plant Breed 44:215-217

Bozhan H, Yang LC, Jiezhen F (1997) Biological effects of laser and ${ }^{60} \mathrm{Co}$ gamma rays on $\mathrm{M}_{1}$ plants of groundnut (Arachis hypogaea L.). Oil Crops China 19:12-14

Branch WD, Hammons RO (1983) Inheritance of a micro phenotype in peanut. Crop Sci 23:1045-1046

Fujioka S, Yamane H, Spray CR, Katsumi M, Phinney BO, Gaskin P, MacMillan J, Takahashi N (1988) The dominant non-gibberellinresponding dwarf mutant $(D 8)$ of maize accumulates native gibberellins. Proc Natl Acad Sci (USA) 85:9031-9035

Gowda MVC, Nadaf HL, Sheshagiri R (1996) The role of mutations in intraspecific differentiation of groundnut (Arachis hypogaea L.). Euphytica 90:105-113

Hong Y, Chen X, Liang X, Liu H, Zhou G, Li S, Wen S, Holbrook CC, Guo B (2010) A SSR-based composite genetic linkage map 
for the cultivated peanut (Arachis hypogaea L.) genome. BMC Plant Biol 10:17

International Rice Research Institute (IRRI) (2003) IRRISTAT for Windows. Version 4.4. International Rice Research Institute, Metro Manila

Kosambi DD (1944) The estimation of map distances from recombination values. Ann Eugen 12:172-175

Levy A, Ashri A (1975) Ethidium bromide - an efficient mutagen in higher plants. Mutation Res 28:397-404

Lincoln SE, Daly MJ, Lander ES (1993) Constructing genetic linkage maps with MAPMAKER EXP Version 3.0: a tutorial and reference manual. A Whitehead Institute of Biomedical Research Technical Report. Available online at: http://www.umanitoba.ca/ afs/plant_science/psgendb/doc/mapmaker/mapmaker.tutorial.pdf

Mondal S, Badigannavar AM (2010) Molecular diversity and association of SSR markers to rust and late leaf spot resistance in cultivated groundnut (Arachis hypogaea L.). Plant Breed 129:68-71

Mondal S, Badigannavar AM, Kale DM, Murty GSS (2007) An induced dominant seed coat colour mutation in groundnut. Indian J Genet Plant Breed 67:177-179

Moretzsohn MC, Leoi L, Proite K, Guimarães PM, Leal-Bertioli SCM, Gimenes MA, Martins WS, Valls JFM, Grattapaglia D, Bertioli DJ (2005) A microsatellite-based, gene-rich linkage map for the AA genome of Arachis (Fabaceae). Theor Appl Genet 111:1060-1071

Murashige T, Skoog F (1962) A revised medium for rapid growth and bioassays with tobacco tissue cultures. Physiol Plant 15:473-497

Patil SH (1966) Mutations induced in groundnut by X-rays. Indian J Genet Plant Breed 26A:334-348

Patil SH, Mouli C (1975) Genetics of a dwarf mutant in groundnut. Theor Appl Genet 46:395-400

Patil SH, Mouli C (1978) Radiation induced bunchy top mutant in groundnut. Current Sci 47:22-23

Phinney BO (1984) Gibberellin A1, dwarfism and the control of shoot elongation in higher plants. In: Crozier A, Hillman JR (eds) The biosynthesis and metabolism of plant hormones. Cambridge University Press, Cambridge, pp 17-41

Reddy MN, Pokojska A, Kampert M, Strezelczyk E (1989) Auxin-, gibberellin-like substances and cytokinins in the seed and root exudates of groundnut. Plant Soil 113:283-286

Tiwari SP, Khanorkar SM (1984) Colchicine induced true breeding miniature mutant in groundnut. Current Sci 53:1262-1263

Ueguchi-Tanaka M, Fujisawa Y, Kobayashi M, Ashikari M, Iwasaki Y, Kitano H, Matsuoka M (2000) Rice dwarf mutant $d 1$, which is defective in the $\alpha$ subunit of the heterotrimeric G protein, affects gibberellin signal transduction. Proc Natl Acad Sci (USA) 97:11638-11643 